\title{
Food group intake and central obesity among children and adolescents in the Third National Health and Nutrition Examination Survey (NHANES III)
}

\author{
M Loring Bradlee, Martha R Singer, M Mustafa Qureshi and Lynn L Moore* \\ Section of Preventive Medicine and Epidemiology, Boston University School of Medicine, Harrison Court, \\ 761 Harrison Avenue, Boston, MA 02118 , USA
}

Submitted 23 October 2008: Accepted 11 August 2009: First published online 22 September 2009

\begin{abstract}
Objective: To explore mean food group intakes associated with central obesity anthropometry among children and adolescents enrolled in the Third National Health and Nutrition Examination Survey (NHANES III).

Design: Cross-sectional study.

Setting: Representative sampling of the US population (1998-2002).

Subjects: Subjects were 3761 children (5-11 years) and 1803 adolescents (12-16 years) with single $24 \mathrm{~h}$ dietary recalls and anthropometric measures of central body fat (waist circumference and sum of subscapular and suprailiac skinfold thicknesses).

Results: Results were controlled for confounding by age, height, race/ethnicity, Tanner stage, television viewing and parental education. In younger children, there was no relationship between central adiposity and mean intakes of dairy, fruit, vegetables or grains, while a positive association with meat intake was found among boys. In adolescent boys and girls, central body fat measures were inversely associated with mean dairy and grain intakes. Adolescent boys in the highest quartile of central adiposity consumed less fruit and fewer vegetables; those in the lowest central adiposity quartile consumed less meat. Finally, adolescents who met the criteria for central obesity (waist circumference $\geq 85$ th percentile for age and sex) reported consuming significantly less total dairy (as well as milk and cheese separately), total grains (whole and refined) and total fruit and vegetables. There was no association with meat consumption. To test the stability of these findings, the final analysis was replicated in 2541 same-aged adolescents from NHANES 1999-2002; the results were very similar.

Conclusions: These cross-sectional analyses suggest that intakes of dairy, grains and total fruits and vegetables are inversely associated with central obesity among adolescents.
\end{abstract}

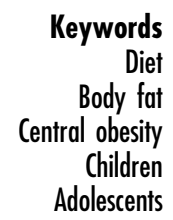

Central obesity is a key component of the metabolic syndrome $^{(1)}$, which is associated with increased risks of CVD and diabetes ${ }^{(2-4)}$. Intra-abdominal visceral fat is particularly reactive to lipolytic stimuli and is believed to affect glucose homeostasis through its effect on circulating adiponectin levels ${ }^{(5)}$. As central obesity is more strongly associated with visceral fat than BMI, waist circumference (WC) has been proposed as the more sensitive measure of relative CVD risk ${ }^{(6,7)}$.

The metabolic syndrome has been identified in children and adolescents ${ }^{(8)}$ as well as adults and appears to persist from childhood into adulthood ${ }^{(9)}$. Trends of increasing overweight ${ }^{(10)}$ and central obesity ${ }^{(11)}$ among children and adolescents are well documented. Some studies indicate that central adiposity among children may be increasing independent of weight ${ }^{(12,13)}$. As a surrogate measure of central body fat, WC has been suggested as an important early marker for the development of chronic diseases ${ }^{(14,15)}$ as well as a practical screening tool for identifying children at risk for metabolic syndrome ${ }^{(16,17)}$.

Although some studies have considered the role of dietary patterns in the development of central obesity among adults ${ }^{(18-21)}$, data related to the role of food group intake in the development of central obesity at younger ages is very limited. The US Department of Agriculture's (USDA) Food Guide Pyramid and Dietary Guidelines for Americans (issued every five years) provide food-based intake guidelines for children and adults ${ }^{(22)}$. Unfortunately, there is little direct scientific evidence to support 
specific dietary recommendations for the prevention of childhood obesity, particularly central obesity. The consumption of different amounts and types of foods may impact adiposity in a variety of direct and indirect ways. For example, different foods may impact satiety through volumetric differences, effects on gastric emptying or energy content. Other foods are theorized to affect body weight through their impact on such factors as energy metabolism or storage, lipogenesis or insulin sensitivity. The goal of the current analyses was to explore the relationship of mean food group intake and anthropometric measures of central obesity in children (aged 5-11 years) and adolescents (aged 12-16 years) using crosssectional data from the Third National Health and Nutrition Examination Survey (NHANES III, 1988-1994).

\section{Methods}

\section{Study population}

NHANES have been conducted regularly since 1960 to assess the health and dietary status of the civilian noninstitutionalized US population aged 2 months and older. The surveys randomly select subjects using a stratified, multistage probability cluster design and oversample certain groups including young children, non-Hispanic blacks and Mexican-Americans. Details of the design and sampling methods as well procedures for obtaining informed consent have been described elsewhere ${ }^{(23)}$. The current secondary analyses were conducted with the approval of the Boston University Institutional Review Board. Since dietary habits may change particularly during late adolescence, we restricted the analyses to subjects who were less than 17 years of age in order to reduce the likelihood that true changes in diet would impact the estimates of usual intake ${ }^{(24)}$.

The primary analyses include subjects who were 5-16 years of age and in one of three categories of racial or ethnic origin: non-Hispanic whites, non-Hispanic blacks and Mexican-Americans. A total of 4329 children aged 5-11 years children (or their parents) and 2079 adolescents aged 12-16 years completed interviews and an examination. The number of subjects $(n 99)$ in the other racial/ethnic groups was insufficient to provide stable estimates of association, so these subjects were excluded from the analyses as has been recommended by the NHANES III Analytic and Reporting Guidelines ${ }^{(25)}$. Subjects with dietary data designated as missing or unreliable ( $n$ 317) by the study nutritionist or with extremes of energy intake (the upper and lower $2 \%$ of the distribution of energy intake; $n$ 227) were excluded, as were those who were pregnant or breast-feeding ( $n$ 18), taking diabetes medication ( $n$ 8), had missing data for WC circumference ( $n$ 128) or had potential confounders of interest to the study ( $n$ 47). This resulted in a final sample size of 3761 children aged 5-11 years and 1803 adolescents aged 12-16 years. Skinfold measurement data were missing for an additional 112 subjects who were therefore excluded from any sub-analyses related to that outcome. Similar exclusion criteria were used for the 1999-2002 NHANES study population of 12- to 16-year-olds, leaving 2541 available for the analysis.

\section{Assessment of dietary intake}

Dietary intake in both NHANES III and NHANES 1999-2002 was assessed through a single $24 \mathrm{~h}$ recall using an automated, microcomputer-based interview ${ }^{(26)}$. Prior to age 12 , the recall was completed jointly by the subject and a proxy respondent. Dietary recalls were analysed for nutrient composition using USDA nutrient files appropriate to the time period.

Food Pyramid servings of the five major food groups (i.e. dairy, fruit, vegetables, grains and meats/other proteins) were calculated from intake of both simple foods (e.g. glass of milk) and mixed dishes (e.g. lasagne) as defined by the USDA Dietary Guidelines ${ }^{(27,28)}$. One dairy serving was defined as 1 cup of milk or yoghurt, $1.5 \mathrm{oz}$ of natural cheese or $2 \mathrm{oz}$ of processed cheese. A fruit serving equalled 1 medium fruit (e.g. apple, banana, orange), 1/2 cup of chopped, cooked or canned fruit, or 3/4 cup of fruit juice. Total fruit (whole or as juice) was also divided into two subgroups: (i) citrus, melons and berries; and (ii) other fruits. One vegetable serving comprised 1 cup of raw leafy vegetables, $1 / 2$ cup of cut-up raw or cooked other vegetables, or $3 / 4$ cup of vegetable juice. There were several vegetable subgroups including dark-green vegetables, deep-yellow vegetables, white potatoes, other starchy vegetables (including legumes), tomatoes and other vegetables. French fries were included with potatoes but the added fat from frying was counted as servings of discretionary fat (see below). A grain serving (whole and refined) was represented by 1 slice of bread, 1 cup of dry cereal, or $1 / 2$ cup of cooked rice, pasta or cereal. Finally, the meat/protein group included all forms of meat, fish, poultry, eggs, soyabean products, nuts and seeds. For the purposes of estimating intake, servings in the meat/other protein group were expressed as ounce equivalents and included items such as $1 \mathrm{oz}$ of lean meat, fish or poultry, 1/2 cup of cooked dry beans, an egg, or 2 tablespoons of peanut butter ${ }^{(29)}$. Discretionary fats referred to fat in food that is above the amount that would be expected in a lean, low-fat or fat-free form of the food.

\section{Assessment of anthropometric measures of central obesity}

WC served as the main measure of central adiposity in these analyses, while the sum of suprailiac and subscapular skinfold thicknesses served as a secondary measure. Waist measurements were taken on a horizontal line at the high point of the iliac crest. The measurement was made at minimal respiration to the nearest $0 \cdot 1 \mathrm{~cm}$. Skinfold thickness measurements were taken using a 
Holtain skinfold calliper following a standard protocol and recorded to the nearest $0.1 \mathrm{~mm}$. For NHANES 1999-2002, only WC was examined as an outcome (the sum of the two skinfolds was not available).

\section{Assessment of potential confounders}

Parental education (classified as less than high school, high school and more than high school) was used as an indicator of socio-economic status (SES). Income was assessed as a secondary measure of SES in these analyses using a dichotomous classification of $<\$ 20000 v$. $\$ 20000$ or more (since nearly $10 \%$ of NHANES III subjects failed to provide more precise data on annual income). In the NHANES III sample, parental education was retained in the final models as it confounded the main results. Since this variable was not available in the 1999-2002 surveys, parental income was used instead. The three categories of race/ethnicity as defined by NHANES included nonHispanic blacks, Hispanic (specifically Mexican-American) and non-Hispanic whites.

Pubertal development was assessed during the physical examination by physicians who were given standardized training in the use of Tanner stage classification ${ }^{(30,31)}$. For the purpose of the present analyses, the original 5-stage Tanner scale was collapsed into three categories: (i) stage 1 or 2; (ii) stage 3; and (iii) stage 4 or 5 . Tanner stage classification was not available for NHANES 1999-2002. Television watching was assessed in both surveys by questioning the child (or parent, depending on age) about the number of hours of television watched the previous day. Weight and standing height were measured according to a standardized protocol and BMI was calculated as weight in kilograms divided by the square of height in metres $\left(\mathrm{kg} / \mathrm{m}^{2}\right)$.

Physical activity was assessed among children aged 8 years and above by questionnaire. We examined it as a potential confounder in the models for adolescents but later dropped it as it led to no change in the results.

\section{Statistical metbods}

Given the cross-sectional study design, both the anthropometry measures and the dietary intakes were measured at the same time. In these analyses, we examined the adjusted mean dietary intakes associated with age- and sex-specific quartiles of WC (and the sum of subscapular and suprailiac skinfold measures). The adjusted mean level of intake in each quartile of central body fat was estimated using analysis of covariance modelling with PROC GLM in the SAS statistical software package version 9·1 (SAS Institute Inc., Cary, NC, USA).

In addition to the use of quartiles for categorizing the distributions of central adiposity, we also examined the association between the mean intakes in each of the five major food groups and related subgroups and the prevalence of central obesity. Since there are no specific cutoff points for defining an abnormal waist size in children, we chose to explore both the 85th and the 90th age- and sex-specific percentiles. Although the 90th percentile of waist size has been used in some guidelines for defining the metabolic syndrome in children ${ }^{(32)}$, we found that the associations between food intake and waist size using the 85th yielded very similar results and greater statistical power and so we present only that analysis. To allow for the comparison of the analysis results from the 1999-2002 surveys with those from NHANES III, we used the same age- and sex-specific cut points of WC (derived from the NHANES III distributions) to define children with ( $\geq 85$ th percentile) and without ( $<85$ th percentile) central obesity.

The potential confounders retained in the final models were those that led to meaningful changes in the adjusted mean dietary intakes, including age, race/ethnicity, height, number of hours of daily television viewing, Tanner stage of pubertal development and parental education or income level. For the approximately $1.5 \%$ of subjects who had missing data on parental education, we used a dummy variable to substitute missing education information. Analyses were conducted including and excluding the dummy variable for education and the results were nearly identical, leading us to conclude that the inclusion of these subjects was unbiased.

\section{Results}

Descriptive characteristics for the 3761 children aged 5-11 years and the 1803 adolescents aged 12-16 years are shown in Table 1. On average, the 5- to 11-year-olds were slightly less than 8 years of age while the adolescents were about 14 years of age. Boys in both age groups consumed more dairy, vegetables, grains and meats/other non-dairy proteins than did girls. While there were no apparent gender-related differences in WC at these ages, girls did have higher levels of subcutaneous fat as assessed by the sum of subscapular and suprailiac skinfolds $(P<0.05$ for all $)$

Tables 2 and 3 show adjusted mean food group intakes according to the age- and sex-specific quartiles of WC and sum of two skinfolds. At 5-11 years of age (Table 2) there were few differences in food intake associated with category of central body fat, although boys in the lowest quartile of WC or sum of two skinfolds consumed about half a serving less of meat/other protein than those in the highest quartile (e.g. 3.61 servings/d $v .4 \cdot 14$ servings/d for WC quartiles 1 and 4, respectively; $P$ for trend $=0 \cdot 025$ ).

Among 12- to 16-year-old male and female adolescents (Table 3), intakes of dairy products and total grains were inversely associated with both measures of central body fat. For example, those in the lowest quartile of WC consumed nearly half a serving more of dairy per day than those in the highest quartile ( $P$ for trend $=0 \cdot 001$ and $0 \cdot 015$ for girls and boys, respectively). Similarly, those in the smallest WC quartile consumed more than one 
Table 1 Characteristics of subjects by age and gender in the Third National Health and Nutrition Examination Survey

\begin{tabular}{|c|c|c|c|c|c|c|c|c|}
\hline & \multicolumn{4}{|c|}{ Age $5-11$ years } & \multicolumn{4}{|c|}{ Age $12-16$ years } \\
\hline & \multicolumn{2}{|c|}{ Females (n 1895) } & \multicolumn{2}{|c|}{ Males ( $n$ 1866) } & \multicolumn{2}{|c|}{ Females ( $n$ 950) } & \multicolumn{2}{|c|}{ Males ( $n$ 853) } \\
\hline & Mean & SD & Mean & SD & Mean & SD & Mean & SD \\
\hline Age (years) & $7 \cdot 7$ & $2 \cdot 1$ & $7 \cdot 8$ & $2 \cdot 1$ & $14 \cdot 0$ & $1 \cdot 4$ & $13 \cdot 9$ & $1 \cdot 4$ \\
\hline Height (in) & $50 \cdot 9$ & $5 \cdot 9$ & $51 \cdot 1$ & $5 \cdot 4$ & $62 \cdot 9$ & $2 \cdot 9$ & $65 \cdot 0^{*}$ & $4 \cdot 3$ \\
\hline Height (cm) & $129 \cdot 3$ & $15 \cdot 0$ & $129 \cdot 8$ & $13 \cdot 7$ & $159 \cdot 8$ & $7 \cdot 4$ & $165 \cdot 1$ & $10 \cdot 9$ \\
\hline Television (h/d) & $2 \cdot 2$ & 1.5 & $2 \cdot 3^{\star}$ & 1.5 & $2 \cdot 3$ & $1 \cdot 7$ & $2 \cdot 3$ & $1 \cdot 6$ \\
\hline Total energy (kJ) & $7313 \cdot 1$ & $2317 \cdot 4$ & $8326 \cdot 7^{*}$ & $2679 \cdot 6$ & $8130 \cdot 8$ & $2996 \cdot 5$ & $10372 \cdot 4^{*}$ & $4133 \cdot 2$ \\
\hline \multicolumn{9}{|l|}{ Food group intake (servings/d) } \\
\hline Dairy & $1 \cdot 9$ & $1 \cdot 2$ & $2 \cdot 2^{*}$ & $1 \cdot 4$ & $1 \cdot 7$ & $1 \cdot 4$ & $2 \cdot 2^{*}$ & $1 \cdot 8$ \\
\hline Fruits & $1 \cdot 4$ & $1 \cdot 6$ & $1 \cdot 4$ & $1 \cdot 6$ & $1 \cdot 0$ & $1 \cdot 5$ & $1 \cdot 1$ & $1 \cdot 7$ \\
\hline Vegetables & $2 \cdot 3$ & $1 \cdot 8$ & $2 \cdot 5^{\star}$ & $2 \cdot 1$ & $2 \cdot 8$ & $2 \cdot 4$ & $3 \cdot 2^{*}$ & $2 \cdot 9$ \\
\hline Grain & $6 \cdot 0$ & $2 \cdot 8$ & $6 \cdot 9^{*}$ & $3 \cdot 4$ & $6 \cdot 3$ & $3 \cdot 4$ & $8 \cdot 5^{\star}$ & $4 \cdot 9$ \\
\hline Meat/Non-dairy proteint & $3 \cdot 4$ & $2 \cdot 4$ & $3 \cdot 9^{*}$ & $2 \cdot 8$ & $4 \cdot 0$ & $3 \cdot 0$ & $5 \cdot 4^{*}$ & 3.9 \\
\hline Waist circumference (cm) & $60 \cdot 0$ & $10 \cdot 1$ & $60 \cdot 4$ & $10 \cdot 3$ & $75 \cdot 4$ & $12 \cdot 0$ & $75 \cdot 6$ & $13 \cdot 3$ \\
\hline \multirow[t]{2}{*}{ Sum of two skinfolds $(\mathrm{mm}) \ddagger$} & $20 \cdot 3$ & $14 \cdot 1$ & $16 \cdot 9^{\star}$ & $13 \cdot 1$ & $33 \cdot 3$ & $16 \cdot 6$ & $24 \cdot 6^{*}$ & $16 \cdot 6$ \\
\hline & $n$ & $\%$ & $n$ & $\%$ & $n$ & $\%$ & $n$ & $\%$ \\
\hline \multicolumn{9}{|l|}{ Race/ethnicity } \\
\hline Non-Hispanic whites & 526 & $27 \cdot 8$ & 511 & $27 \cdot 4$ & 266 & $28 \cdot 0$ & 208 & $24 \cdot 4$ \\
\hline Non-Hispanic blacks & 631 & $33 \cdot 3$ & 640 & $34 \cdot 3$ & 346 & $36 \cdot 4$ & 305 & $35 \cdot 7$ \\
\hline Mexican-American & 738 & $38 \cdot 9$ & 715 & $38 \cdot 3$ & 338 & $35 \cdot 6$ & 340 & $39 \cdot 9$ \\
\hline \multicolumn{9}{|l|}{ Parental education $\ddagger$} \\
\hline Less than high school & 785 & $42 \cdot 1$ & 731 & $39 \cdot 9$ & 385 & $40 \cdot 9$ & 363 & $42 \cdot 8$ \\
\hline High school & 577 & $31 \cdot 0$ & 590 & $32 \cdot 2$ & 298 & $31 \cdot 7$ & 282 & $33 \cdot 3$ \\
\hline More than high school & 501 & $26 \cdot 9$ & 510 & $27 \cdot 9$ & 258 & $27 \cdot 4$ & 203 & $23 \cdot 9$ \\
\hline
\end{tabular}

*Mean value was significantly different from that of females $(P<0.05)$.

+Meat/Non-dairy protein = total ounce servings of meat, fish, poultry and other non-dairy sources of protein.

‡Data were missing for subscapular skinfold ( $n 37)$, suprailiac skinfold $(n 54)$, both skinfolds $(n 21)$ and parental education $(n 81)$.

Table 2 Adjusted mean food intakes according to anthropometric measures of central obesity: children aged 5-11 years (Third National Health and Nutrition Examination Survey)

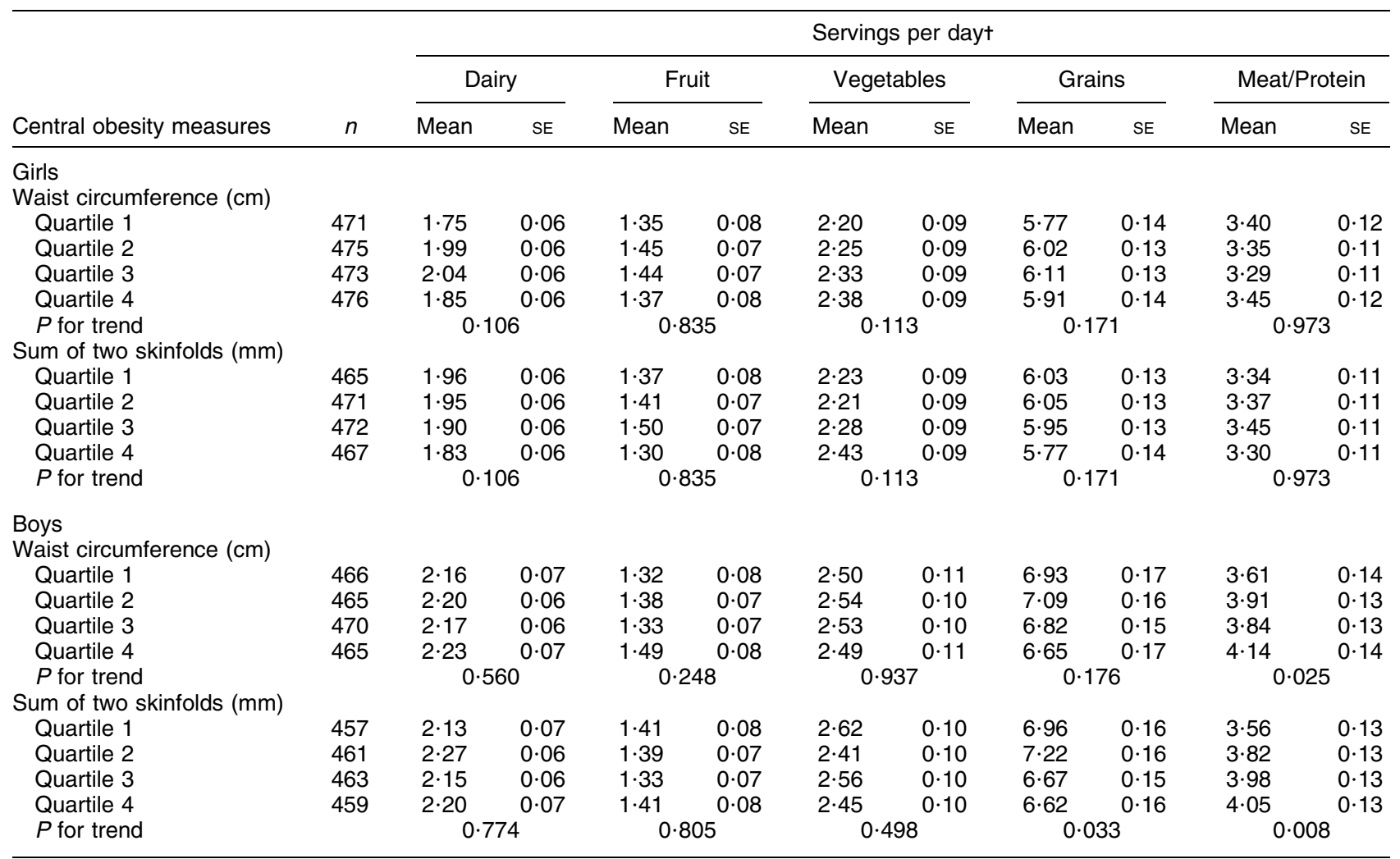

†Food group means are adjusted for exact age, height, race/ethnicity, hours per day watching television, Tanner stage and parental education. 
Table 3 Adjusted mean food intakes according to anthropometric measures of central obesity: adolescents aged 12-16 years (Third National Health and Nutrition Examination Survey)

\begin{tabular}{|c|c|c|c|c|c|c|c|c|c|c|c|}
\hline \multirow[b]{3}{*}{ Central obesity measures } & \multirow[b]{3}{*}{$n$} & \multicolumn{10}{|c|}{ Servings per dayt } \\
\hline & & \multicolumn{2}{|c|}{ Dairy } & \multicolumn{2}{|c|}{ Fruit } & \multicolumn{2}{|c|}{ Vegetables } & \multicolumn{2}{|c|}{ Grains } & \multicolumn{2}{|c|}{ Meat/Protein } \\
\hline & & Mean & SE & Mean & SE & Mean & SE & Mean & SE & Mean & SE \\
\hline \multicolumn{12}{|l|}{ Girls } \\
\hline \multicolumn{12}{|l|}{ Waist circumference $(\mathrm{cm})$} \\
\hline Quartile 1 & 235 & $1 \cdot 76$ & 0.09 & $1 \cdot 05$ & $0 \cdot 10$ & $2 \cdot 70$ & $0 \cdot 16$ & $6 \cdot 76$ & $0 \cdot 23$ & $3 \cdot 96$ & $0 \cdot 20$ \\
\hline Quartile 2 & 239 & $1 \cdot 86$ & 0.09 & $1 \cdot 10$ & $0 \cdot 10$ & 3.03 & $0 \cdot 15$ & $6 \cdot 53$ & $0 \cdot 22$ & $4 \cdot 13$ & $0 \cdot 19$ \\
\hline Quartile 3 & 238 & 1.67 & 0.09 & 0.99 & $0 \cdot 10$ & $2 \cdot 71$ & $0 \cdot 16$ & $6 \cdot 18$ & $0 \cdot 22$ & $3 \cdot 95$ & $0 \cdot 19$ \\
\hline Quartile 4 & 238 & $1 \cdot 34$ & 0.09 & $1 \cdot 04$ & $0 \cdot 10$ & $2 \cdot 66$ & $0 \cdot 16$ & $5 \cdot 64$ & 0.22 & 3.94 & 0.20 \\
\hline$P$ for trend & & \multicolumn{2}{|c|}{0.001} & \multicolumn{2}{|c|}{0.762} & \multicolumn{2}{|c|}{0.521} & \multicolumn{2}{|c|}{0.0003} & \multicolumn{2}{|c|}{0.773} \\
\hline \multicolumn{12}{|l|}{ Sum of two skinfolds (mm) } \\
\hline Quartile 1 & 224 & $1 \cdot 86$ & $0 \cdot 10$ & 0.96 & $0 \cdot 10$ & $2 \cdot 73$ & $0 \cdot 16$ & $6 \cdot 83$ & $0 \cdot 23$ & 3.99 & $0 \cdot 20$ \\
\hline Quartile 2 & 230 & 1.68 & 0.09 & $1 \cdot 13$ & $0 \cdot 10$ & $2 \cdot 82$ & $0 \cdot 15$ & $6 \cdot 51$ & 0.23 & $3 \cdot 90$ & $0 \cdot 20$ \\
\hline Quartile 3 & 231 & $1 \cdot 72$ & 0.09 & 1.03 & $0 \cdot 10$ & $2 \cdot 91$ & $0 \cdot 15$ & $6 \cdot 14$ & $0 \cdot 23$ & $4 \cdot 06$ & $0 \cdot 20$ \\
\hline Quartile 4 & 226 & $1 \cdot 44$ & $0 \cdot 10$ & $1 \cdot 12$ & $0 \cdot 10$ & $2 \cdot 52$ & $0 \cdot 16$ & $5 \cdot 70$ & 0.23 & $4 \cdot 01$ & $0 \cdot 20$ \\
\hline$P$ for trend & & \multicolumn{2}{|c|}{0.006} & \multicolumn{2}{|c|}{0.443} & \multicolumn{2}{|c|}{0.446} & \multicolumn{2}{|c|}{0.0003} & \multicolumn{2}{|c|}{$0 \cdot 806$} \\
\hline \multirow{2}{*}{\multicolumn{12}{|c|}{$\begin{array}{l}\text { Boys } \\
\text { Waist circumference }(\mathrm{cm})\end{array}$}} \\
\hline & & & & & & & & & & & \\
\hline Quartile 1 & 213 & $2 \cdot 48$ & $0 \cdot 13$ & $1 \cdot 33$ & $0 \cdot 13$ & 3.33 & $0 \cdot 21$ & $8 \cdot 87$ & $0 \cdot 35$ & $4 \cdot 87$ & $0 \cdot 28$ \\
\hline Quartile 2 & 211 & $2 \cdot 22$ & $0 \cdot 12$ & $1 \cdot 28$ & $0 \cdot 12$ & $3 \cdot 22$ & $0 \cdot 20$ & $8 \cdot 80$ & 0.33 & $5 \cdot 33$ & 0.27 \\
\hline Quartile 3 & 215 & $2 \cdot 02$ & $0 \cdot 12$ & 0.99 & $0 \cdot 12$ & 3.39 & $0 \cdot 20$ & $8 \cdot 61$ & 0.33 & $5 \cdot 72$ & 0.27 \\
\hline Quartile 4 & 214 & $2 \cdot 05$ & $0 \cdot 13$ & 0.95 & $0 \cdot 12$ & $2 \cdot 87$ & 0.21 & $7 \cdot 56$ & 0.34 & $5 \cdot 63$ & 0.27 \\
\hline$P$ for trend & & \multicolumn{2}{|c|}{0.015} & \multicolumn{2}{|c|}{0.016} & \multicolumn{2}{|c|}{0.016} & \multicolumn{2}{|c|}{0.011} & \multicolumn{2}{|c|}{0.047} \\
\hline \multicolumn{12}{|l|}{ Sum of two skinfolds (mm) } \\
\hline Quartile 1 & 207 & $2 \cdot 37$ & $0 \cdot 13$ & $1 \cdot 30$ & $0 \cdot 12$ & $3 \cdot 42$ & $0 \cdot 21$ & $9 \cdot 35$ & 0.35 & $4 \cdot 88$ & $0 \cdot 28$ \\
\hline Quartile 2 & 205 & $2 \cdot 31$ & $0 \cdot 12$ & $1 \cdot 30$ & $0 \cdot 12$ & $3 \cdot 25$ & $0 \cdot 20$ & $8 \cdot 88$ & $0 \cdot 34$ & $5 \cdot 57$ & $0 \cdot 27$ \\
\hline Quartile 3 & 208 & $2 \cdot 14$ & $0 \cdot 12$ & 1.08 & $0 \cdot 12$ & $3 \cdot 31$ & $0 \cdot 20$ & $8 \cdot 15$ & $0 \cdot 34$ & $5 \cdot 45$ & 0.27 \\
\hline Quartile 4 & 206 & $2 \cdot 04$ & $0 \cdot 13$ & $0 \cdot 89$ & $0 \cdot 12$ & $2 \cdot 93$ & 0.21 & $7 \cdot 67$ & $0 \cdot 34$ & $5 \cdot 61$ & 0.28 \\
\hline$P$ for trend & & \multicolumn{2}{|c|}{0.047} & & & & & & & & \\
\hline
\end{tabular}

tFood group means are adjusted for exact age, height, race-ethnicity, hours per day watching TV, Tanner stage, and parental education.

additional serving of grain per day than those in the highest quartile ( $P$ for trend $=0.0003$ and 0.011 for girls and boys, respectively). Neither fruit nor vegetable intake was associated with central adiposity in girls. However, adolescent boys with the largest waist (and skinfold) measures consumed the least amount of fruit ( $P$ for trend $=0.016$ and 0.012 for WC and skinfolds, respectively) and the fewest vegetables ( $P$ for trend $=0.016$ for WC). Finally, there was also a tendency for adolescent boys in the lowest quartile of WC to consume less meat ( $P$ for trend $=0 \cdot 047$ ).

Table 4 examines the association between food intake and central obesity by classifying those with $\mathrm{WC}$ at or above the age- and sex-specific 85th percentile as having central obesity. We conducted the analyses in both NHANES III and NHANES 1999-2002. The analyses in Table 4 are restricted to adolescents. Identical analyses were carried out among 5- to 11-year-old children (not shown) but, as was found in Table 2, there were no meaningful or statistically significant differences in the major food group intakes associated with WC. In both surveys, adolescents with central obesity (WC $\geq 85$ th percentile) consumed less dairy and fewer grains and had lower intakes of total fruit and vegetables $(P=0.0002$, $P<0.0001$ and $P=0.045$, respectively, in NHANES III; $P=0.0009, P=0.0002$ and $P=0.062$, respectively, in
NHANES 1999-2002). While the majority of the dairy consumed was in the form of milk, both milk $(P=0 \cdot 004)$ and cheese intakes $(P=0 \cdot 020)$ were inversely associated with central obesity in NHANES III while only the association with milk consumption was significantly different $(P=0.0008)$ in the later NHANES sample; too few subjects consumed yoghurt to evaluate its effect separately. Central obesity was similarly related to whole and refined grain intakes $(P=0.002$ and $P=0.001$, respectively, in NHANES III; $P=0.006$ and $P=0.003$, respectively, in NHANES 1999-2002). There was no consistent association between central obesity and the intake of meat and meat equivalents. Finally, we compared the discretionary fat intakes of children with and without central obesity, and found that children without central obesity reported consuming more discretionary fat than children with central obesity $(P<0.0001$ in NHANES III; $P=0.003$ in NHANES 1999-2002).

\section{Discussion}

The present paper explores the relationship between food group intake and central obesity among children and adolescents. The results suggest that intakes of dairy and grains as well as the combined intakes of fruit and 
Table 4 Association between food intake and waist size in adolescents in NHANES III and NHANES 1999-2002

\begin{tabular}{|c|c|c|c|c|c|c|c|c|c|c|}
\hline \multirow{4}{*}{$\begin{array}{l}\text { Total food groups } \\
\text { and subgroups }\end{array}$} & \multicolumn{5}{|c|}{ Servings per dayt } & \multicolumn{5}{|c|}{ Servings per daył } \\
\hline & \multicolumn{5}{|c|}{ NHANES III } & \multicolumn{5}{|c|}{ NHANES 1999-2002 } \\
\hline & \multicolumn{2}{|c|}{$\begin{array}{c}\text { WC }<85 \text { th } \\
\text { percentile§ }(n 1517)\end{array}$} & \multicolumn{2}{|c|}{$\begin{array}{c}W C \geq 85 \text { th } \\
\text { percentile } \$(n 286)\end{array}$} & \multirow[b]{2}{*}{$P$ value } & \multicolumn{2}{|c|}{$\begin{array}{c}\text { WC }<85 \text { th } \\
\text { percentile§ }(n \text { 1509) }\end{array}$} & \multicolumn{2}{|c|}{$\begin{array}{c}\mathrm{WC}<85 \text { th } \\
\text { percentile }(n \text { 284) }\end{array}$} & \multirow[b]{2}{*}{$P$ value } \\
\hline & Mean & SE & Mean & SE & & Mean & SE & Mean & SE & \\
\hline Dairy (total) & $1 \cdot 97$ & 0.04 & 1.58 & $0 \cdot 10$ & 0.0002 & 1.92 & 0.04 & $1 \cdot 68$ & 0.06 & 0.0009 \\
\hline Milk & $1 \cdot 32$ & 0.03 & $1 \cdot 06$ & 0.08 & $0 \cdot 004$ & $1 \cdot 27$ & 0.03 & $1 \cdot 05$ & 0.06 & 0.0008 \\
\hline Cheese & $0 \cdot 64$ & 0.02 & $0 \cdot 51$ & 0.05 & $0 \cdot 020$ & $0 \cdot 64$ & 0.02 & $0 \cdot 61$ & 0.03 & 0.505 \\
\hline Fruit and vegetables (total) & $4 \cdot 13$ & 0.08 & $3 \cdot 72$ & $0 \cdot 19$ & 0.045 & $4 \cdot 07$ & $0 \cdot 07$ & $3 \cdot 79$ & $0 \cdot 13$ & 0.062 \\
\hline Fruit (total) & $1 \cdot 11$ & 0.04 & 0.98 & $0 \cdot 10$ & 0.234 & $1 \cdot 37$ & $0 \cdot 04$ & $1 \cdot 14$ & 0.08 & 0.012 \\
\hline Citrus, melon, berries & $0 \cdot 61$ & 0.03 & 0.46 & 0.07 & 0.062 & 0.68 & 0.03 & 0.63 & 0.06 & $0 \cdot 401$ \\
\hline Other fruit & 0.50 & 0.03 & 0.52 & 0.06 & $0 \cdot 775$ & $0 \cdot 68$ & 0.03 & 0.51 & 0.05 & 0.003 \\
\hline Vegetables (total) & $3 \cdot 02$ & 0.07 & $2 \cdot 74$ & $0 \cdot 16$ & $0 \cdot 102$ & $2 \cdot 71$ & 0.06 & $2 \cdot 65$ & $0 \cdot 10$ & 0.640 \\
\hline Dark green & 0.08 & 0.01 & 0.05 & 0.03 & $0 \cdot 307$ & 0.06 & 0.01 & 0.09 & 0.01 & $0 \cdot 102$ \\
\hline Deep yellow/orange & 0.08 & $0 \cdot 01$ & 0.08 & 0.02 & 0.964 & 0.09 & $0 \cdot 01$ & 0.07 & 0.01 & $0 \cdot 188$ \\
\hline $\begin{array}{l}\text { Potatoes (white) \& other } \\
\text { starchy }\end{array}$ & $1 \cdot 66$ & 0.05 & $1 \cdot 49$ & $0 \cdot 12$ & $0 \cdot 207$ & $1 \cdot 47$ & 0.04 & $1 \cdot 43$ & 0.08 & 0.673 \\
\hline $\begin{array}{l}\text { Other vegetables (including } \\
\text { tomatoes) }\end{array}$ & $1 \cdot 21$ & 0.03 & $1 \cdot 12$ & 0.08 & 0.333 & $1 \cdot 09$ & 0.03 & $1 \cdot 07$ & 0.05 & $0 \cdot 701$ \\
\hline Grains (total) & $7 \cdot 50$ & $0 \cdot 11$ & $6 \cdot 30$ & $0 \cdot 25$ & $<0.0001$ & $7 \cdot 30$ & 0.09 & $6 \cdot 61$ & $0 \cdot 16$ & 0.0002 \\
\hline Refined grains & $6 \cdot 58$ & $0 \cdot 10$ & $5 \cdot 70$ & $0 \cdot 24$ & 0.001 & $6 \cdot 51$ & 0.09 & $5 \cdot 99$ & $0 \cdot 15$ & 0.003 \\
\hline Whole grains & 0.92 & 0.04 & $0 \cdot 60$ & 0.09 & 0.002 & $0 \cdot 79$ & 0.03 & 0.62 & 0.05 & 0.006 \\
\hline Meat and other protein (total) & $4 \cdot 65$ & 0.09 & $4 \cdot 69$ & $0 \cdot 21$ & $0 \cdot 856$ & $4 \cdot 30$ & 0.08 & $4 \cdot 24$ & $0 \cdot 13$ & $0 \cdot 730$ \\
\hline Red meat (beef, pork, lamb) & 1.97 & 0.07 & $1 \cdot 90$ & $0 \cdot 15$ & 0.651 & $1 \cdot 68$ & 0.06 & $1 \cdot 77$ & $0 \cdot 10$ & 0.404 \\
\hline $\begin{array}{l}\text { Processed (franks, } \\
\text { sausage, luncheon meats) }\end{array}$ & $0 \cdot 76$ & 0.04 & $0 \cdot 72$ & 0.09 & 0.692 & $0 \cdot 74$ & 0.03 & $0 \cdot 79$ & $0 \cdot 06$ & $0 \cdot 450$ \\
\hline Poultry, fish, shellfish & $1 \cdot 41$ & 0.07 & 1.57 & $0 \cdot 16$ & 0.359 & $1 \cdot 46$ & 0.05 & $1 \cdot 19$ & 0.09 & 0.013 \\
\hline Eggs, nuts, seeds, soya & $0 \cdot 50$ & 0.02 & 0.50 & 0.06 & 0.975 & 0.42 & 0.02 & 0.48 & 0.04 & $0 \cdot 106$ \\
\hline Nuts and seeds & $0 \cdot 17$ & 0.02 & $0 \cdot 14$ & 0.04 & 0.479 & $0 \cdot 11$ & $0 \cdot 01$ & $0 \cdot 11$ & 0.01 & 0.662 \\
\hline Discretionary fat (g) & $66 \cdot 98$ & $0 \cdot 87$ & $55 \cdot 52$ & $2 \cdot 03$ & $<0.0001$ & $63 \cdot 63$ & $0 \cdot 76$ & $59 \cdot 04$ & $1 \cdot 32$ & 0.003 \\
\hline
\end{tabular}

NHANES, National Health and Nutrition Examination Survey; WC, waist circumference.

tAdjusted for exact age, gender, height, race/ethnicity, hours per day watching television, Tanner stage and parental education.

$\ddagger$ Adjusted for exact age, gender, height, race/ethnicity, hours per day watching television and parental income.

$\S$ Age- and gender-specific cut-off points of WC from the NHANES III data set were used.

vegetables are associated with lower levels of central body fat, particularly among adolescents.

The literature related to dietary intake and central obesity in children is very limited. These results are consistent with a report from the National Growth and Health Study which found that adolescent white females following a 'healthy dietary pattern' (i.e. higher intakes of dairy, fruits, vegetables and grains) had smaller increases in WC over 10 years $^{(33)}$. A larger number of studies have examined the relationship of food group intake and overall adiposity among children. Regarding dairy, for instance, some data indicate that higher dairy intakes are associated with significantly lower body fat levels through childhood ${ }^{(34-36)}$, although a review of the evidence in 2005 concluded that there was insufficient evidence at that time to draw firm conclusions regarding the effect of Ca or dairy intake on body fat ${ }^{(37)}$.

While higher fruit and vegetable consumption is thought to be associated with a healthy body weight in children, a recent review concluded that more evidence is needed to support this conclusion ${ }^{(38)}$ and it has been suggested that the methods of preparation (e.g. frying) and serving (e.g. with sauce) may account for the apparent inconsistent protective effect. Data on the relationship of grains and weight in children are limited. One prospective study demonstrated smaller annual weight change in relation to each additional serving of breads/grains ${ }^{(39)}$ and another ${ }^{(40)}$ found that cereal consumption was related to lower BMI; neither of these studies distinguished between refined and whole grains. In the current cross-sectional study, we saw that adolescents whose waist circumference was above the 85th percentile reported consuming less discretionary fat than those with less central body fat. There are several possible explanations for this finding. First, reporting bias is a possibility, with more under-reporting of added fat among children with more central adiposity. It could be, however, that more overweight adolescents are in fact consuming less added fat. For example, in our own observations (ML Singer and LL Moore, unpublished results), we found that overweight children and adolescents more often consumed low-fat dairy products than those who are of normal weight. Finally, we note that discretionary fat does not necessarily reflect the total fat load of 
the diet. The correlations between discretionary fat and percentage of energy from total fat were 0.56 and 0.58 in NHANES III and NHANES 1999-2002 samples, respectively.

Several studies have examined food group intake and central obesity among adults. One such cross-sectional study of middle-aged adults found an inverse relationship between a dietary pattern characterized by frequent intake of raw and salad vegetables and seasonal fruits (and low intakes of fried foods including potatoes) and central obesity ${ }^{(18)}$. One prospective study found that a pattern characterized by high intakes of fruit, vegetables, reduced-fat dairy and whole grains and low intakes of red and processed meat was associated with smaller gains in central obesity ${ }^{(18)}$, while another found an inverse association between a dietary pattern of high fruits and vegetables and low-fat dairy and WC among women ${ }^{(41)}$. The CARDIA study identified an inverse association between higher dairy intake and lower waist:hip ratio among young adults ${ }^{(42)}$ and at least one small trial found dairy to be inversely related to central fat loss among obese subjects $^{(43)}$. Similar results have been found for whole grain consumption and cereal fibre ${ }^{(44,45)}$. In terms of meat intake, high intakes of both red and processed meat have been shown to be positively related to the likelihood of central weight gain over a 10 -year period in several studies ${ }^{(46,47)}$.

A number of possible explanations exist for the findings of these studies. Dairy foods have been hypothesized to be associated with lower levels of body fat through the effects of their Ca content on lipogenesis ${ }^{(48)}$. Dairy is also an important source of protein and protein-rich diets have been shown to promote satiety ${ }^{(49)}$. The dairy protein, whey, is also a rich source of the essential amino acid leucine that is involved in the partitioning of dietary energy ${ }^{(50)}$. The effects of whole grains on obesity are believed to relate to their soluble fibre content, which is associated with increased satiety, delayed gastric emptying and enhanced insulin sensitivity ${ }^{(51,52)}$. Fruits and vegetables are also important sources of fibre and may have similar effects on satiety and satiation ${ }^{(53)}$.

The limitations of our exploratory study must be acknowledged. As with any self-reported dietary record, there is the real possibility of misrepresentation of dietary intake. Subjects for whom weight or body proportions are of concern may certainly tend to understate aspects of their intake. The cross-sectional design of NHANES also prevents any conclusions related to cause and effect.

The availability of a single day's dietary recall limits the precision of the estimated dietary intakes of individuals. However, a single $24 \mathrm{~h}$ dietary recall provides accurate estimates of mean dietary intake within groups ${ }^{(54)}$. Thus, the recalls used in NHANES are appropriate for quantifying mean food intakes associated with quartiles of central body fat.

The NHANES data set offers important strengths as well. The large, randomly selected group of children and adolescents provides sufficient power to explore a broad range of intake levels in different food groups. The availability of data from each of the USDA Food Pyramid groups, including information from single food sources and mixed dishes, is a strength of the study. Most studies of food effects on health outcomes have relied on intakes from FFQ, which yield less precise estimates of food servings from all sources. For example, it is not possible to extract the actual number of grain servings from all sources in an FFQ since many of the servings would be derived from composite foods such as pizza or lasagne.

In summary, the current cross-sectional study demonstrates an association between the patterns of food intake during adolescence and the prevalence of excess central body fat. The intakes of dairy and grains, especially whole grains, as well as total fruits and vegetables were inversely associated with central obesity among these adolescents. These associations were not fully explained by total body fat as measured by BMI.

The USDA provides food-based dietary guidelines that are specific to age, sex and physical activity level. Prospective studies are needed to test the effects of these recommendations on the development of central obesity in children and adolescents. The present study is an important first step towards such future work.

\section{Acknowledgements}

Ethics approval: All analyses were conducted with the approval of the Boston University Institutional Review Board. Sources of funding: The data analysis detailed in the manuscript was partially funded by the National Dairy Council (Rosemont, IL, USA). The National Dairy Council was not, however, directly involved in the study design, data collection, analysis or interpretation of results. Conflict of interest declaration: None. Authorship contributions: M.R.S. was responsible for initial data management and nutritional input. M.M.Q. conducted analyses and contributed to creation of tables. M.L.B. performed the literature search and wrote the manuscript. L.L.M. designed the analysis and edited the final draft of the manuscript.

\section{References}

1. Eckel RH, Grundy SM \& Zimmet PZ (2005) The metabolic syndrome. Lancet 365, 1415-1428.

2. Isomaa B, Almgren P, Tuomi T, Forsén B, Lahti K, Nissén M, Taskinen MR \& Groop L (2001) Cardiovascular morbidity and mortality associated with the metabolic syndrome. Diabetes Care 24, 683-689.

3. Wilson PWF, D'Agostino RB, Parise H, Sullivan L \& Meigs JB (2005) Metabolic syndrome as a precursor of cardiovascular disease and type 2 diabetes mellitus. Circulation 112, 3066-3072.

4. Grundy SM, Cleeman JI, Daniels SR et al. (2005) Diagnosis and management of the metabolic syndrome: an American Heart Association/National Heart, Lung, and Blood Institute 
Scientific Statement: Executive Summary. Circulation 112, $2735-2752$.

5. Steffes MW, Gross MD, Schreiner PJ, Yu X, Hilner JE, Gingerich R \& Jacobs DR Jr (2004) Serum adiponectin in young adults - interactions with central adiposity, circulating levels of glucose, and insulin resistance: the CARDIA study. Ann Epidemiol 14, 492-498.

6. Dobbelsteyn CJ, Joffres MR, MacLean DR \& Flowerdew G (2001) A comparative evaluation of waist circumference, waist-to-hip ratio and body mass index as indicators of cardiovascular risk factors. The Canadian Heart Health Surveys. Int J Obes Relat Metab Disord 25, 652-661.

7. Janssen I, Katzmarzyk PT \& Ross R (2002) Body mass index, waist circumference and health risk. Arch Intern Med 162, 2074-2079.

8. Bitsori M \& Kafatos A (2005) Dysmetabolic syndrome in childhood and adolescence. Acta Paediatr 94, 995-1005.

9. Huang TT-K, Ball GDC \& Franks PW (2007) Metabolic syndrome in youth: current issues and challenges. Appl Physiol Nutr Metab 32, 13-22.

10. Ford ES, Mokdad AH \& Ajani UA (2004) Trends in risk factors for cardiovascular disease among children and adolescents in the United States. Pediatrics 114, 1534-1544.

11. Li C, Ford ES, Mokdad AH \& Cook S (2006) Recent trends in waist circumference and waist-height ratio among children and adolescents. Pediatrics 118, e1390-e1398.

12. McCarthy HD, Jarrett KV, Emmett PM \& Rogers I (2005) Trends in waist circumference in young British children: a comparative study. Int J Obes (Lond) 29, 157-162.

13. Moreno LA, Sarría A, Fleta J, Marcos A \& Bueno M (2005) Secular trends in waist circumference in Spanish adolescents, 1995 to 2000-02. Arch Dis Child 90, 818-819.

14. Maffeis C, Pietrobelli A, Grezzani A, Provera S \& Tatò L (2001) Waist circumference and cardiovascular risk factors in prepubertal children. Obes Res 9, 179-187.

15. Savva SC, Tornaritis M, Savva ME, Kourides Y, Panagi A, Silikiotou N, Georgiou C \& Kafatos A (2000) Waist circumference and waist-to-height ratio are better predictors of cardiovascular disease risk factors in children than body mass. Int J Obes Relat Metab Disord 24, 1453-1458.

16. Hirschler V, Aranda C, Calcagno Mde L, Maccalini G \& Jadzinsky M (2005) Can waist circumference identify children with the metabolic syndrome? Arch Pediatr Adolesc Med 159, 740-744.

17. Moreno LA, Pineda I, Rodríguez G, Fleta J, Sarría A \& Bueno M (2002) Waist circumference for the screening of the metabolic syndrome in children. Acta Paediatr 91, 1307-1312.

18. Williams DE, Prevost T, Whichelow MJ, Cox BD, Day NE \& Wareham NJ (2000) A cross-sectional study of dietary patterns with glucose intolerance and other features of the metabolic syndrome. Br J Nutr $\mathbf{8 3}, 257-266$.

19. Wirfält E, Hedblad B, Gullberg B, Mattison I, Andrén C, Rosander U, Janzon L \& Berglund G (2001) Food patterns and components of the metabolic syndrome in men and women: a cross-sectional study within the Malmö Diet and Cancer Cohort. Am J Epidemiol 154, 1150-1159.

20. Newby PK, Muller D, Hallfrisch J, Qiao N, Andres R \& Tucker KL (2003) Dietary patterns and changes in body mass index and waist circumference in adults. Am J Clin Nutr 77, 1417-1425.

21. Drapeau V, Despres J-P, Bouchard C, Allard L, Fournier G, Leblanc C \& Tremblay A (2004) Modifications in foodgroup consumption are related to long-term body-weight changes. Am J Clin Nutr 80, 29-37.

22. US Department of Health and Human Services \& US Department of Agriculture (2005) Dietary Guidelines for Americans, 2005, 6th ed. Washington, DC: US Government Printing Office.
23. Ezzati TM, Massey JT, Waksberg J, Chu A \& Maurer KR (1992) Sample design: Third National Health and Nutrition Examination Survey. Vital Health Stat 2 issue 113, 1-35.

24. von Post-Skågegard $M$, Samuelson $G$, Karlström $B$, Mohsen R, Berglund L \& Bratteby L-E (2002) Changes in food habits in healthy Swedish adolescents during the transition from adolescence to adulthood. Eur J Clin Nutr 56, 532-538.

25. National Center for Health Statistics, Centers for Disease Control and Prevention (1996) Analytic and Reporting Guidelines: the Third Health and Nutrition Examination Survey, NHANES III (1988-94). Hyattsville, MD: NCHS/ CDC; available at http://www.cdc.gov/nchs/data/nhanes/ nhanes3/nh3gui.pdf

26. Feskanich D, Sielaff BH, Chong K \& Buzzard IM (1989) Computerized collection and analysis of dietary intake information. Comput Methods Programs Biomed 30, 47-57.

27. US Department of Agriculture \& US Department of Health and Human Services (1995) Nutrition and Your Health: Dietary Guidelines for Americans. Home and Garden Bulletin no. 232, 4th ed. Washington, DC: US Government Printing Office.

28. US Department of Agriculture \& US Department of Health and Human Services (2000) Nutrition and Your Health: Dietary Guidelines for Americans. Home and Garden Bulletin no. 232, 5th ed. Washington, DC: US Government Printing Office.

29. Friday JE \& Bowman SA (2006) MyPyramid Equivalents Database for USDA Survey Food Codes, 1994-2002, Version 1.O. Washington, DC: US Department of Agriculture, Agriculture Research Service; available at http:// www.barc.usda.gov/bhnrc/cnrg

30. Marshall WA \& Tanner JM (1969) Variations in pattern of pubertal changes in girls. Arch Dis Child 44, 291-303.

31. Marshall WA \& Tanner JM (1970) Variation in the pattern of pubertal changes in boys. Arch Dis Child 45, 13-23.

32. Zimmet P, Alberti KG, Kaufman F, Tajima N, Silink M, Arslanian S, Wong G, Bennett P, Shaw J \& Caprio S; IDF Consensus Group (2007) The metabolic syndrome in children and adolescents - an IDF consensus report. Pediatr Diabetes 8, 299-306.

33. Ritchie LD, Spector P, Stevens MJ, Schmidt MM, Schreiber GB, Striegel-Moore RH, Wang MC \& Crawford PB (2007) Dietary patterns in adolescence are related to adiposity in young adulthood in black and white females. J Nutr 137, 399-406.

34. Novotny R, Daida YG, Acharya S, Grove JS \& Vogt TM (2004) Dairy intake is associated with lower body fat and soda intake with greater weight in adolescent girls. $J$ Nutr 134, 1905-1909.

35. Barba G, Troyano E, Russo P, Venecia A \& Siani A (2005) Inverse association between body mass and frequency of milk consumption in children. Br J Nutr 93, 15-19.

36. Moore LL, Bradlee ML, Gao D \& Singer MR (2006) Low dairy intake in early childhood predicts excess body fat gain. Obes Res 14, 1010-1018.

37. Huang TT \& McCrory MA (2005) Dairy intake, obesity, and metabolic health in children and adolescents: knowledge and gaps. Nutr Rev 63, 71-80.

38. Newby PK (2007) Are dietary intakes and eating behaviors related to childhood obesity? A comprehensive review of the evidence. J Law Med Ethics 35, 35-60.

39. Newby PK, Peterson KE, Berkey CS, Leppert J, Willett WC \& Colditz GA (2003) Dietary composition and weight change among low-income preschool children. Arch Pediatr Adolesc Med 157, 759-764.

40. Barton BA, Eldridge AL, Thompson D, Affenito SG, Striegel-Moore RH, Franko DL, Albertson AM \& Crockett SJ (2005) The relationship of breakfast and cereal consumption to nutrient intake and body mass index: 
The National Heart, Lung, and Blood Institute Growth and Health Study. J Am Diet Assoc 105, 1383-1389.

41. McNaughton SA, Mishra GD, Stephen AM \& Wadsworth MEJ (2007) Dietary patterns throughout adult life are associated with body mass index, waist circumference, blood pressure and red cell folate. J Nutr 137, 99-105.

42. Pereira MA, Jacobs DR Jr, Van Horn L, Slattery ML, Kartashov AI \& Ludwig DS (2002) Dairy consumption, obesity, and the insulin resistance syndrome in young adults: the CARDIA study. JAMA 287, 2081-2089.

43. Zemel MB, Richards J, Mathis S, Milstead A, Gebhardt L \& Silva E (2005) Dairy augmentation of total and central fat loss in obese subjects. Int J Obes (Lond) 29, 391-397.

44. Ludwig DS, Pereira MA, Kroenke CH, Hilner JE, Van Horn L, Slattery ML \& Jacobs DR Jr (1999) Dietary fiber, weight gain, and cardiovascular disease risk factors in young adults. JAMA 282, 1539-1546.

45. Newby PK, Maras J, Bakun P, Muller D, Ferrucci L \& Tucker KL (2007) Intake of whole grains, refined grains, and cereal fiber measured with 7-d diet records and associations with risk factors for chronic disease. Am J Clin Nutr 86, $1745-1753$.

46. Kahn HS, Tatham LM, Rodriguez C, Calle EE, Thun MJ \& Heath CW (1997) Stable behaviours associated with adults' 10-year change in body mass index and likelihood of gain at waist. Am J Public Health 87, 747-754.
47. Wagemakers JJMF, Prynne CJ, Stephen AM \& Wadsworth MEJ (2009) Consumption of red or processed meat does not predict risk factors for coronary heart disease; results from a cohort of British adults in 1989 and 1999. Eur J Clin Nutr 63, 303-311.

48. Zemel MB (2004) Role of calcium and dairy products in energy partitioning and weight management. Am J Clin Nutr 79, 907S-912S.

49. Luhovyy BL, Akhavan T \& Anderson GH (2007) Whey proteins in the regulation of food intake and satiety. $J \mathrm{Am}$ Coll Nutr 26, 704S-712S.

50. Layman DK (2003) The role of leucine in weight loss diets and glucose homeostasis. J Nutr 133, 261S-267S.

51. Slavin J (2004) Whole grains and human health. Nutr Res Rev 17, 99-110.

52. Koh-Banerjee P \& Rimm EB (2003) Whole grain consumption and weight gain: a review of the epidemiological evidence, potential mechanisms, and opportunities for future research. Proc Nutr Soc 62, 25-29.

53. Rolls BJ, Ello-Martin JA \& Tohill BC (2004) What can intervention studies tell us about the relationship between fruit and vegetable consumption and weight management? Nutr Rev 62, 1-17.

54. Carrera PM, Xiang G \& Tucker KL (2007) A study of dietary patterns in the Mexican-American population and their association with obesity. J Am Diet Assoc 107, 1735-1742. 